ACT A C H E I C A S C A N D I N A I C A 19 (1965) $661-669$

\title{
The Melting Point of Alumina and Some Related Observations
}

\author{
GUNNAR GITLESEN and KETIL MOTZFELDT
}

\begin{abstract}
Royal Norwegian Council for Scientific and Industrial Research, Metallurgical Committee; The Technical University of Norway, Trondheim, Norway
\end{abstract}

\begin{abstract}
A method is described for the observation of melting points for high-melting oxides, and the melting point of alumina is determined to $2041^{\circ} \mathrm{C}$. The result is corroborated by thermal analysis and by observation of the melting point of platinum. Some additional observations on the sub-cooling and pre-melting behaviour of alumina are described.
\end{abstract}

In conjunction with an investigation of the system $\mathrm{Al}-\mathrm{C}-\mathrm{O}$ and its

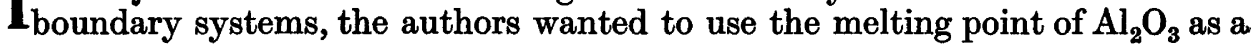
reference point for the temperature measurements. This met with two difficulties; first, that agreement has not yet been reached regarding the correct melting point of alumina, and second, that no really reliable method has been established for the observation of melting points for high-melting oxides.

Schneider ${ }^{1}$ has recently presented a thorough survey of the reported melting points of the oxides. For alumina, he lists a total of 15 references from the years 1911 to 1961 , with reported values ranging from about $2000^{\circ}$ to about $2050^{\circ} \mathrm{C}$. The majority of these investigations were done by optical pyrometry and visual examination of the sample, with the rounding of sharp. edges, the melting of the tip of a cone or similar observations taken to indicate the start of melting. As will be related below, these criteria are not reliable for the present purpose. The value $2050^{\circ} \mathrm{C}$, obtained by Kanolt ${ }^{2}$ in 1914 , was determined by thermal analysis in heating. Schneider ${ }^{3}$ has reconsidered Kanolts original observations and calculated that they correspond to a melting point of $2072^{\circ} \mathrm{C}$ on the 1948 International Practical Temperature Scale. This is regarded by Schneider to be the best value. On the other hand, Kantor et al. ${ }^{4}$ in a recent investigation of the heat content of alumina using a drop-calorimeter, determined the melting point to $2042 \pm 4^{\circ} \mathrm{C}$, and Chekhovskoi and Petrov ${ }^{5}$ report the value $2044 \pm 4^{\circ} \mathrm{C}$, obtained by means of thermal analysis. 


\section{EQUIPMENT AND PYROMETRY}

The experiments presently to be reported were done in a furnace consisting essentially of a r esistance-heated graphite tube (36 $\mathrm{mm}$ I.D. by $230 \mathrm{~mm}$ long *) mounted in a vacuum-

* Machined from graphite quality AUC supplied by Skandinaviska Grafitindustri Aktiebolaget, Trollhättan, Sweden; a subsidiary of Union Carbide Corporation, USA. Ash content stated by the manufacturer max. $0.08 \%$, average $0.03 \%$.

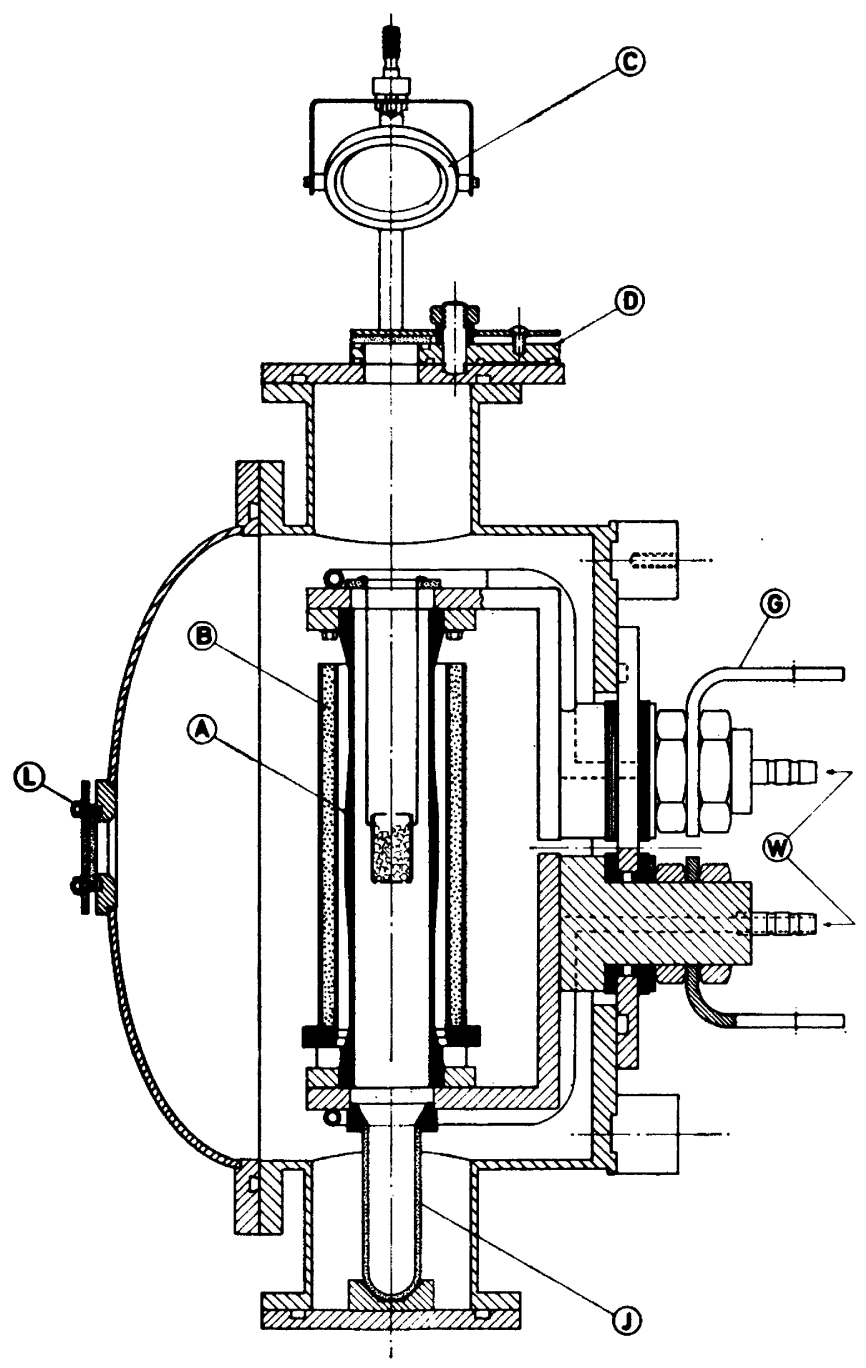

Fig. 1. Cross-section of vacuum furnace. A: Graphite tube heater. B: Carbon felt for thermal insulation. C: Mirror. D: Revolving disc with three silica glass windows for radiation pyrometry. G: Current terminals. W: Water cooling (cooling tubes on vacuum enclosure not shown). J: Silica tube for drip experiments. L: Silica glass window for observation of drip. (Pump opening behind heater tube, $100 \mathrm{~mm}$ diameter, not shown.) 
tight brass enclosure with silica glass windows for observation. The wall thickness of the heater was reduced towards both ends to compensate for the extra heat loss at the ends. A cross section of the furnace is shown in Fig. 1.

The heater current was taken from a low-voltage transformer which was fed from a continuously variable primary transformer fitted with a 10-speed motor and wormgear drive to give suitable heating or cooling rates. After evacuation to about $10^{-5}$ torr and degassing overnight at 1000 to $1200^{\circ} \mathrm{C}$, the melting-point runs were done under a pressure of about 400 torr of argon. Various samples of alumina were used, contained in molybdenum crucibles shaped to approximate black-body conditions. The crucibles were placed out of contact with the graphite in the furnace.*

Temperature was measured with a disappearing-filament optical pyrometer.** In the course of the investigation, two pyrometers of this type were used. The pyrometers were checked against a tungsten-strip lamp calibrated at the National Physical Laboratory, England.***

The radiation from the hot sample passed through a silica glass window (on top of the furnace) and was reflected by a mirror, before reaching the pyrometer. Corrections for absorption in the window and mirror were determined by separate experiment with source temperature in the vicinity of $2000^{\circ} \mathrm{C}$. The corrections were expressed in terms of "A" values, ${ }^{6}$ and thus adjusted to the temperature of the melting-point run.

\section{PRELIMINARY EXPERIMENTS. PREMELTING AND SUBCOOLING}

The first method tried was that of thermal analysis, using a total-radiation pyrom. eter $\dagger$ connected to a potentiometric recorder. This pyrometer in itself is uncalibrated, and true temperature was established by comparison with the disappearing-filament pyrometer at suitable points during the run. Fig. 2 shows a typical recorder tracing. During heating, a sloping halt is observed in the range 2040 to $2050^{\circ} \mathrm{C}$. In general, the halt would be expected to be more well-defined in cooling because of the better thermal transport in the liquid phase. As seen from Fig. 2, however, no thermal arrest is noticeable down to about $1850^{\circ} \mathrm{C}$, where a sharp increase in the temperature indicates sudden solidification. The solidification was also visible to the naked eye as a sudden flash of light. This subcooling of 150 to $200^{\circ}$, in itself an interesting phenomenon, occurred in every experiment, and this type of thermal analysis was finally abandoned. Chekovskoi and Petrov, ${ }^{5}$ on the other hand, report cooling curves for alumina with no mention of sub-cooling. The reason for this difference is unkown.

Next, it was tried to determine the point of melting by visual observation of a small cylindrical sample. As is also pointed out by Schneider: ${ }^{1}$ If the sample is heated under black-body conditions its contours cannot be seen, and conversely, if the contours can be seen, black-body conditions do not prevail and the temperature measurement will be uncertain. To circumvent this problem, a small (about $1 \mathrm{~mm}$ diameter) hole was drilled axially through the sample, which was placed in a molybdenum container with a small hole in the bottom matching that of the sample. Thus, when sighting with the pyrometer through the hole in the lid of the container during the run, the hole in the sample appeared as a black dot in the center of the target area. This black dot, however,

* Some reader might object to the use of a graphite tube for heating an oxide to the temperatures in question. But the vapour pressure of carbon is only about $1 \times 10^{-5}$ torr at $2000^{\circ} \mathrm{C}$, i.e., much too small to cause significant interaction in the presence of an inert gas. The older reports on the "carbonizing" effects observed in carbon tube furnaces are chiefly due to the use of nitrogen or hydrogen atmospheres; none of these gases are inert towards carbon at elevated temperatures.

** Cat. No. 8622-C manufactured by Leeds and Northrup Co., Philadelphia, USA. For stationary use we remove the null galvanometer from the instrument as supplied, and replace it with an external galvanometer of at least tenfold better sensitivity. This has been found to improve the reproducibility of the observations.

*** Lamp Identification No. 17A, calibration report dated 22nd February, 1960.

† Small-target Radiamatic Pyrometer, manufactured by Minneapolis-Honeywell Regulator Co., Philadelphia, USA.

Acta Chem. Scand. 19 (1965) No. 3 


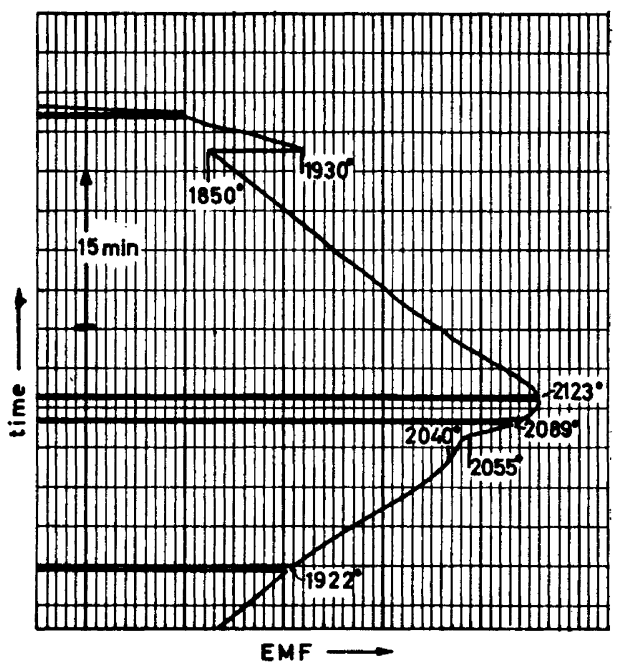

Fig. 2. Recorder tracing from thermal analysis of alumina by means of a totalradiation pyrometer. Horizontal interruptions indicate that a mirror has been flicked into the radiation path, to check the temperature by means of the optical pyrometer.

disappeared already some fifty to a hundred degrees below the expected melting point. Inspection of the sample after several such runs showed that the hole was closed up and previously sharp edges were rounded, at temperatures where the sample had not melted.* Similar observations have also been reported by previous investigators., The effect is not caused by any phase change, but is probably due to a partial destruction of the structure near the melting point.'

The use of the electrical conductance of the sample to detect the phase change ${ }^{10}$ was also considered. Unfortunately the electron emission from metallic conductors at temperatures of $1800^{\circ} \mathrm{C}$ and higher is sufficient to give high apparent conductance between two metal electrodes, regardless of whether the surrounding space is evacuated or filled with an inert gas. This renders the conductivity method an inconvenient one for use above $1800^{\circ} \mathrm{C}$, and it was consequently abandoned.

\section{THE DRIP METHOD}

After these unsuccessful attempts, the authors contemplated that the one sure criterion of melting is that the sample turns into a liquid. In the case of alumina it was also known that the viscosity of the liquid is quite low. ${ }^{11}$ Hence a very simple idea was conceived: The point of melting might be observed by the effect that part of the sample runs out of a hole in the bottom of the crucible. A crucible arrangement as indicated in Fig. 3 was used, suspended in molybdenum wires from the top of the furnace. The holes in the bottom were displaced with respect to the sighting hole in the lid in order not to appear in the target area of the pyrometer (bearing in mind that alumina is translucent). A closed-end silica-glass tube was attached to the lower end of the graphite heater tube inside the vacuum enclosure, to receive the molten alumina. For

\footnotetext{
* Riley ${ }^{7}$ has quite recently described a similar "peephole method" with crosswise observation, which is less subject to errors from possible pre-melting phenomena.
} 
Fig. 3. Cell types used for determination of the melting point by the drip method.

(a) Made from $0.2 \mathrm{~mm}$ Mo sheet, (b) turned from solid Mo stock.

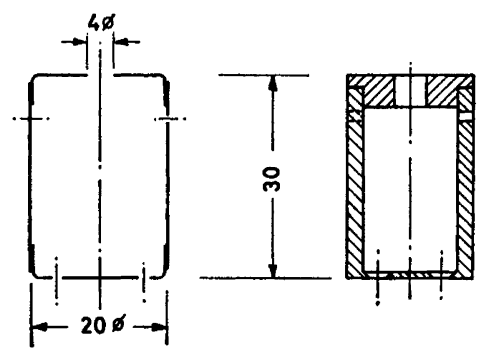

(a)

(b)

these experiments, coarsely crushed samples of recrystallized-alumina tubes * were used.

After evacuation, degassing and admission of argon, the furnace was heated rapidly to about $1850^{\circ} \mathrm{C}$, and from then on at a rate about $5^{\circ} / \mathrm{min}$. One observer read the temperature every minute while another called out time from a stopwatch, simultaneously watching the lower end of the furnace through a side-window in the enclosure. At the first appearance of melt dripping, clearly visible as sharp flashes of light in the silica tube, the stopwatch was triggered and the heating discontinued.

Fig. 4 shows the time-temperature curve for one such run. The accuracy of the drip method in itself is good because the moment of melting can be determined very accurately, while the temperature is determined by the linear extrapolation of several observations, so that the slight scatter of individual

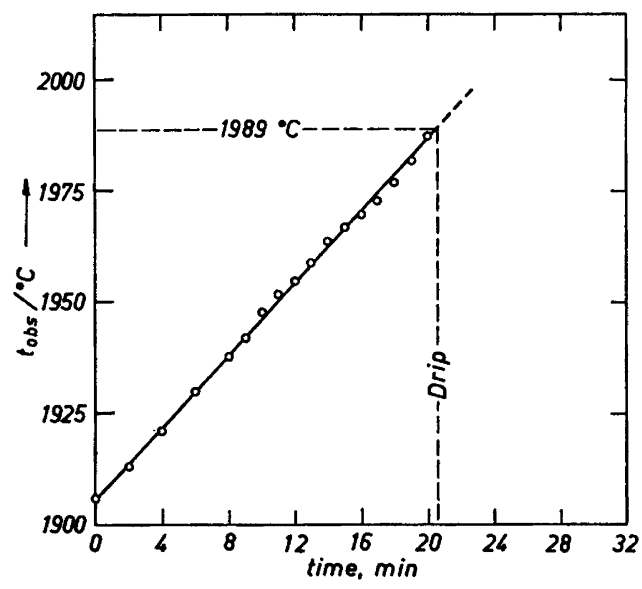

Fig. 4. Observed (i.e., uncorrected) temperature versus time for a drip experiment (run No. 4 in Table 1).

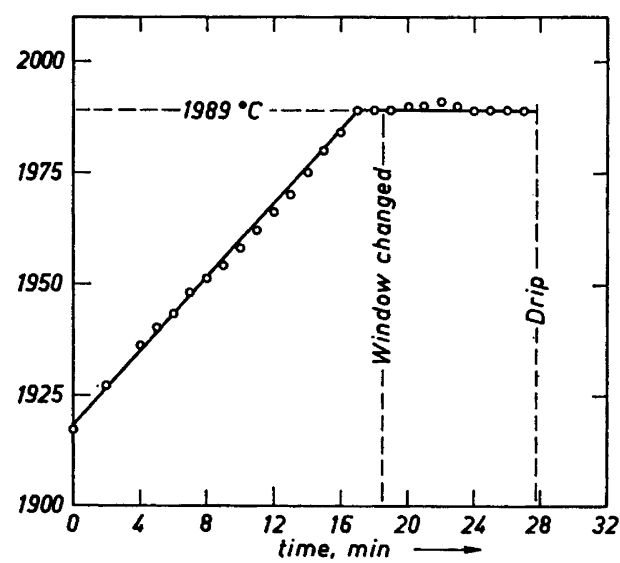

Fig. 5. Observed temperature versus time for run No. 5 of Table 1.

* Alumina $\triangle R R$ manufactured by Morgan Crucible Co., England. According to the manufacturer, the $\mathrm{Al}_{2} \mathrm{O}_{3}$ content is not less than $99.7 \%$, the impurities consist mainly of sodium and iron oxides, normally less than $0.1 \%$ of either.

Acta Chem. Scand. 19 (1965) No. 3 
readings is smoothed. Thus the correctness of the result depends almost exclusively on the absolute accuracy of the pyrometry.

Several experiments of this kind were performed, with slight variations in shape and position of the crucible. It was then found that in some runs the drip was preceded by a halt in the heating curve (cf. Fig. 5), and in others only a long halt and no drip occurred. It is evident that a certain minimum size of the drip holes and a certain liquid head are necessary to overcome the surface tension of the liquid. With a head of about $10 \mathrm{~mm}$, holes with diameter $1.6 \mathrm{~mm}$ were found sufficient for crucibles made from $0.2 \mathrm{~mm}$ Mo sheet, while a larger hole size was required for thick-bottom crucibles made from solid Mo stock. Furthermore the relation between halt and drip is dependent on the exact temperature distribution on the crucible, which in turn is determined by its position in the heater. Thus, a drip with no preceding halt could be produced by placing the center of the crucible a few $\mathrm{mm}$ above the center of the heater tube, so that the bottom of the crucible was slightly hotter than its top.

Table 1 summarizes the results, with notice as to whether the melting point is determined by drip, halt, or both. Included in the table are also the corrections for window and mirror, and for the pyrometers relative to the standard lamp. The last four runs are considered to be the more reliable, with an average value of $2041^{\circ} \mathrm{C}$ for the melting point of alumina.

The determination of the corrections for window and mirror require particular attention, since any error on this point will give the same error in the final result. In runs Nos. 1 and 2 it was assumed that the absorption in the mirror, determined at an earlier time, remained constant, and only the absorption in the window was determined separately for each run. A renewed check on the mirror, however, revealed that its absorption had increased, probably because of a slight tarnishing of the first-surface mirror used in these experiments when exposed to the laboratory atmosphere. As a consequence, the results of runs 1 and 2 (obtained with the earlier $A$ value for the mirror) are slightly low. From run No. 4 on, the A value for the combination of window and mirror was determined after each run; this procedure also has the advantage of reducing the number of separate observations that go into the final result. For this and other reasons, the last four runs are given preference.

Samples of the alumina collected in the silica tube after run No. 2, as well as of the remainder in the crucible, were subjected to spectrographic analysis * with the following results

$\begin{array}{llc} & \text { Dripped } & \text { Remainder } \\ \mathrm{Fe} & 0.18 \% & 0.10 \% \\ \mathrm{Mo} & 0.001 & 0.006\end{array}$

In both samples were found traces of $\mathrm{Mg}, \mathrm{Ca}, \mathrm{Cr}$, and $\mathrm{Mn}$, in amounts of $0.001 \%$ or less; Si was not found.

The iron content reflects the fact that the samples prior to the runs were crushed in a hardened-steel mortar; the slight contamination thus caused will be located on the surface of the grains and consequently will be enriched in the dripped portion. The molybdenum contamination, on the other hand, is larger in the portion remaining in the Mo crucible, but it is of a negligible magnitude. Allowing for a maximum of $0.1 \% \mathrm{Fe}$ in the original sample would correspond to maximum $0.13 \% \mathrm{FeO}$. From the phase diagram $\mathrm{FeO}-\mathrm{Al}_{2} \mathrm{O}_{3}{ }^{12}$ it is found that the corresponding freezing-point depression will be less than $1^{\circ}$. Thus the correction for impurities may be neglected.

* The analyses were kindly performed by the Department of Chemistry, The Geological Survey of Norway, Trondheim. 
Table 1. Results for the melting point of alumina.

\begin{tabular}{|c|c|c|c|c|c|c|}
\hline $\begin{array}{l}\text { Run } \\
\text { No. }\end{array}$ & $\begin{array}{l}t_{\text {obs }} \\
{ }^{\circ} \mathbf{C}\end{array}$ & $\mathbf{A}_{\mathbf{w}+\mathbf{m}}$ & $\Delta t_{\mathbf{w}}+\mathbf{m}$ & $\Delta t_{\mathrm{pyr}}$ & ${ }^{t_{\mathrm{corr}}^{\circ} \mathrm{C}}$ & $\begin{array}{c}\text { Observed } \\
\text { by }\end{array}$ \\
\hline 1 & 1984 & $(1.00)$ & 52 & -3 & 2033 & Drip \\
\hline $\mathbf{2}$ & 1985 & $(1.00)$ & 52 & $-\mathbf{3}$ & 2034 & Drip \\
\hline 3 & 1975 & 1.43 & 76 & -14 & 2037 & Halt \\
\hline 4 & 1989 & 1.27 & 67 & -14 & 2042 & Drip \\
\hline 5 & 1989 & 1.25 & 66 & -14 & 2041 & Halt + Drip \\
\hline " & 1989 & 1.22 & 64 & -14 & 2039 & Second window * \\
\hline 6 & 1995 & 1.11 & 59 & -14 & 2040 & Halt + Drip \\
\hline 7 & 1998 & 1.07 & 57 & -14 & 2041 & Drip \\
\hline
\end{tabular}

* Cf. Fig. 5 .

\section{A CHECK ON THE MELTING POINT OF PLATINUM}

It is seen from Table 1 that, with the deviations between tungsten strip lamp and pyrometer calibrations taken into account, the results are entirely dependent on the calibration of the tungsten strip lamp. It was therefore deemed desirable to attempt a check on our temperature scale by independent means. Among the secondary reference points listed in the International

Fig. 6. Cell for observation of melting point for a metal (platinum) wire.

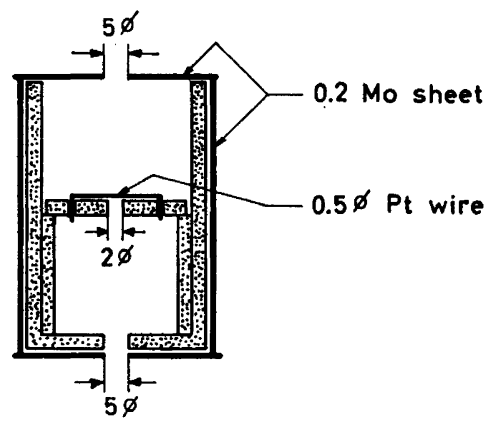

Practical Temperature Scale of $1948,{ }^{13}$ the melting point of platinum was chosen for the purpose. The cost of platinum prevented the use of both the thermal analysis and the drip method, and a wire-melting method was employed.

The cell arrangement for this method is shown in Fig. 6. The inner cell of alumina was enveloped in molybdenum sheet to obtain near-blackbody conditions. The wire was pure platinum of thermocouple quality. When viewed through the pyrometer telescope during the run, the wire appeared as a bright strip against the dark background formed by the bottom hole. The procedure during the run was the same as described for the drip experiments, with the exception that in the present case the same observer read temperature and noted the moment of disappearance of the Pt-wire. A graph of the observations looks very similar to Fig. 4 and hence is not reproduced here. With corrections for window 
and mirror, the observed melting point of platinum was $1783^{\circ}$, read on pyrometer II. With the correct melting point taken as $1769^{\circ} \mathrm{C},{ }^{13}$ the correction for pyrometer II comes to $-14^{\circ}$, in excellent agreement with the value found by means of the tungsten lamp.*

\section{DISCUSSION}

The result for the melting point of alumina, $2041^{\circ} \mathrm{C}$, is in very good agreement with the Russian observations, ${ }^{4,5}$ and makes the higher value suggested by Schneider ${ }^{1,3}$ appear doubtful. Regarding the probable limits of error for the value reported here, it should be remembered that, in the $2000^{\circ} \mathrm{C}$ range, the employed pyrometer can be adjusted and read reproducibly to better than $\pm 2^{\circ}$ only with the uttermost care $\left( \pm 2^{\circ}\right.$ corresponds to $\pm 0.5 \mathrm{~mm}$ on the pyrometer scale). The limits of error for the calibration of the tungsten lamp are given as $\pm 7^{\circ}$, but in wiew of the very good agreement with the melting point of platinum, these limits appear to be rather conservative. Hence it seems justified to apply the same limits to the melting point value reported here, which is thus given as $2041 \pm 7^{\circ} \mathrm{C}$.

A few words have to be added concerning the difference in shape of the two heating curves Figs. 2 and 5. It is probable that the total-radiation pyrometer has received some radiation also from the wall of the sighting tube or from the crucible lid, while the observer with the disappearing-filament pyrometer may focus attention on the significant target only. Thus the latter instrument may be regarded less convenient but more reliable, even for the purpose of thermal analysis.

Regarding the pre-melting behaviour of alumina, Figs. 4 and 5 exhibit a common feature which appeared in all of the experiments with alumina: The observed temperature falls below the straight line in a region some $20-30^{\circ}$ below the melting point. The deviations are small and on the border of experimental uncertainty, but some significance may be attached to them when it is noted that the experimental heat capacities of Kantor et al. ${ }^{4}$ show small, positive deviations for the last $50^{\circ}$ below the melting point. These effects seem to indicate that the pre-melting behaviour mentioned above is connected with a slight increase in the heat capacity, as would also be expected.

\section{REFERENCES}

1. Schneider, S. J. Natl. Bur. Std. (U. S.), Monograph 68 (Washington Oct. 10, 1963).

2. Kanolt, C. W. Natl. Bur. Std. Bull. 10 (1914) 295; J. Wash. Acad. Sci. 3 (1913) 315; Z. anorg. Chem. 85 (1914) 1.

3. Schneider, S. J. J. Am. Ceram. Soc. 46 (1963) 354.

4. Kantor, P. B., Lazareva, L. S., Kandyba, V. V. and Fomichov, E. M. Ukr. Fiz. Zh. 7 (1962) 205.

5. Chekhovskoi, V. Ya. and Petrov, V. A. Izmeritel. Tekhn. No. 91963 26; Engl. Transl. Meas. Tech. (Febr. 1964) 751.

* The corrections relative to the tungsten strip lamp for the observed temperatures 1524 , 1700,1844 , and $2061^{\circ} \mathrm{C}$ (where each figure represents the average of four observations) were found to $-13,-13,-16$, and $-14^{\circ}$, respectively. The deviations from a mean value of $-14^{\circ}$ is within experimental uncertainty so that the correction has been considered constant within the temperature range considered. 
6. See e.g., Kostkowski, H. J. and Lee, R. D. In Brickwedde, F. G. Temperature, Vol. III-1, Reinhold Publ. Co., New York 1962, pp. 449-86.

7. Riley, B. J. Sci. Instr. 41 (1964) 504.

8. Geller, R. F. and Yavorsky, P. J. J. Res. Natl. Bur. Std. 34 (1945) 395.

9. Kozlovskii, A. L. and Shlyakova, K. S. Tr. Vses. Nauchn.-Issled. Inst. Avtogen. Obrabotki Metal. 6 (1960) 136; Chem. Abstr. 55 (1961) 16062.

10. Gitlesen, G. and Motzfeldt, K. Acta Chem. Scand. 18 (1964) 488.

11. Mackenzie, J. D. Advan. Inorg. Chem. Radiochem. 4 (1962) 293.

12. Fischer, W. A. and Hoffman, A. Arch. Eisenhüttenw. 27 (1956) 343.

13. Stimson, H. F. J. Res. Natl. Bur. Std. 65 A (1961) 139.

Received December 27, 1964. 